\title{
Retrospective review of bone mineral metabolism management in end-stage renal disease patients wait-listed for renal transplant
}

This article was published in the following Dove Press journal:

Transplant Research and Risk Management

23 August 2012

Number of times this article has been viewed

\author{
Anna Chavlovski' \\ Greg A Knoll ${ }^{1-3}$ \\ Timothy Ramsay ${ }^{4}$ \\ Swapnil Hiremath ${ }^{1-3}$ \\ Deborah L Zimmerman ${ }^{1-3}$ \\ 'University of Ottawa, ${ }^{2}$ Ottawa \\ Hospital, ${ }^{3}$ Kidney Research Centre, \\ Ottawa Hospital Research Institute, \\ ${ }^{4}$ Ottawa Methods Centre, Ottawa, \\ ON, Canada
}

Correspondence: Deborah Zimmerman Home Hemodialysis, Ottawa Hospital, Riverside Campus, 1967 Riverside Dr, Ottawa, ON KOA 2Z0, Canada

Tel +l 6137388400 ext 82534

$\mathrm{Fax}+\mathrm{I} 6137388337$

Email dzimmerman@ottawahospital.on.ca
Background: In patients with end-stage renal disease, use of vitamin D and calcium-based phosphate binders have been associated with progression of vascular calcification that might have an impact on renal transplant candidacy. Our objective was to examine management of mineral metabolism in patients wait-listed for renal transplant and to determine the impact on cardiac perfusion imaging.

Methods: Data was collected retrospectively on patients wait-listed for a renal transplant $(n=105)$, being either active $(n=73)$ or on hold $(n=32)$. Demographic data, medications, serum concentrations of calcium, phosphate, parathyroid hormone, and cardiac perfusion imaging studies were collected from the electronic health record. Chi-square and Student's $t$-tests were used to compare active and on-hold patients as appropriate. Logistic regression was used to examine variables associated with worsening cardiac imaging studies.

Results: The wait-listed patients were of mean age $56 \pm 14$ years and had been on dialysis for $1329 \pm 867$ days. On-hold patients had received a significantly greater total dose of calcium $(2.35 \pm .94 \mathrm{~kg}$ versus $1.49 \pm 1.52 \mathrm{~kg} ; P=0.02)$ and were more likely to have developed worsening cardiovascular imaging studies $(P=0.03)$. Total doses of calcium and calcitriol were associated with worsening cardiovascular imaging studies $(P=0.05)$.

Conclusion: Patients on hold on the renal transplant waiting list received higher total doses of calcium. A higher total dose of calcium and calcitriol was also associated with worsening cardiovascular imaging. Time on dialysis before transplant has been associated with worse post-transplant outcomes, and it is possible that the total calcium and calcitriol dose received contributed to these inferior outcomes.

Keywords: dialysis, calcium, cardiac, transplantation

\section{Introduction}

Patients with end-stage renal disease (ESRD) have a significantly greater age and gender-adjusted risk of cardiovascular mortality compared with the general population. ${ }^{1}$ Although many traditional cardiovascular risk factors have been implicated, ${ }^{2}$ the population attributable to risk secondary to mineral metabolism abnormalities has been estimated to be approximately $17.5 \%{ }^{3}$ Medications used to manage mineral metabolism abnormalities, such as vitamin D and calcium-based phosphate binders, may also contribute to enhanced cardiovascular disease. ${ }^{4,5}$ Sevelamer hydrochloride, a non-calcium-based phosphate binder, has been associated with decreased progression of cardiovascular calcification when compared with a calcium-based phosphate binder at 52 weeks of therapy, despite similar phosphate control. ${ }^{6}$ The use of this medication is limited in some regions secondary to restricted reimbursement policies because of a 
lack of convincing benefit with respect to mortality. ${ }^{7,8}$ At the Ottawa Hospital, almost all patients on dialysis are treated with calcium-based phosphate binders and calcitriol to control serum phosphate and parathyroid hormone levels. Only patients with private insurance or who develop hypercalcemia in addition to hyperphosphatemia and hyperparathyroidism qualify for a government-assisted financial subsidy for noncalcium-based phosphate binders.

The mean waiting time for a renal transplant in the US, Canada, and UK is approximately 3 years. ${ }^{9-11}$ It is unclear if the mineral metabolism abnormalities and management of these conditions over the prolonged waiting times may contribute to enhanced vascular disease for wait-listed patients, ultimately impacting on renal transplant candidacy. Accordingly, the objectives of this study were twofold, ie, to examine the management of mineral metabolism in patients with ESRD who were wait-listed for renal transplant and to explore the potential contribution of mineral metabolism management to clinically significant vascular calcification in wait-listed patients.

\section{Materials and methods Patient population}

We undertook a retrospective cohort study that included patients on the Ottawa Hospital renal transplant waiting list after obtaining approval from the hospital research ethics board. Eligible patients included those older than 18 years of age with ESRD and treated by hemodialysis or peritoneal dialysis. A total of 158 patients were identified on the transplant waiting list at the time of data collection in July 2010. One hundred and five patients met our inclusion criteria and had complete data, with 73 patients being active and 32 patients being on hold (infection, vascular disease, hyperparathyroidism) on the renal transplant waiting list. The majority of patients were excluded secondary to dialysis in a satellite unit or renal center in which we did not have access to their laboratory values or medication history. Each patient was assigned an identification number and entered into a database.

\section{Study design}

Descriptive data were collected retrospectively from July 31 , 2010 to time of wait-listing using information available from the electronic health record. Data collected included age, gender, date of ESRD, dialysis modality, date of listing for transplant (usually the same as date of ESRD), and diabetes mellitus status. Information on medication was collected with a focus on mineral metabolism. Specifically, it was noted whether patients were prescribed calcium carbonate, vitamin D (cholecalciferol), calcitriol, sevelamer hydrochloride, lanthanum, and/or cinacalcet. Total and average daily doses were calculated for calcium carbonate (as elemental calcium), calcitriol, ie, $1,25(\mathrm{OH})_{2} \mathrm{D}_{3}$, and vitamin $\mathrm{D}$, ie, $25(\mathrm{OH}) \mathrm{D}_{3}$, from the time of transplant list date until July 31 , 2010. This information is updated every $4-8$ weeks in the electronic health record by the dialysis nurse as part of routine clinical practice. In the event that a time period did not specify the dose of calcium carbonate, we conservatively assumed that the patient was taking $200 \mathrm{mg}$ of elemental calcium with meals. Standard dialysate calcium is $1.25 \mathrm{mmol} / \mathrm{L}$ for both hemodialysis and peritoneal dialysis, and this was not considered in the total daily calcium intake. Serum concentrations of calcium, phosphate, and intact parathyroid hormone collected at the time of wait-listing for transplant were also included in the database.

Lastly, the results of myocardial perfusion imaging (persantine, dipyridamole rubidium 82) were collected from the Ottawa Hospital database as a measure of clinically significant vascular calcification. As per Ottawa Hospital protocol, patients with a history of ischemic heart disease, peripheral vascular disease, diabetes mellitus, previous renal transplant, cigarette smoking, hyperlipidemia, hypertension, body mass index $>30$, or age $>50$ years undergo a stress myocardial perfusion imaging that is repeated every 2 years. At least two consecutive myocardial imaging studies since diagnosis of ESRD were used to determine the evolution of cardiovascular disease and were classified as improved, stable, or worsened disease, as described by the interpreting cardiologist. Specifically, we looked for the above words or synonyms in the test results narrative to categorize patients. If these words were not specifically found, but there was clear evidence of stability (eg, a test interpreted as normal both times was judged to be unchanged) or change (eg, a first test interpreted as normal and a second test interpreted as evidence of ischemia was judged to be worsened), patients were categorized accordingly. At the time of this study, cardiac territories were not reported in the electronic medical record. The ejection fraction documented during myocardial imaging was also collected. Those patients without at least two cardiac imaging studies were not included in the myocardial imaging analysis.

\section{Statistical analysis}

Descriptive statistics were calculated to describe the overall population and to compare those patients who were active on the waiting list versus those who were on hold. Data are reported as the mean \pm standard deviation or median 
and interquartile range depending on data distribution. The Student's $t$-test, Chi-square test, and Fisher's Exact test were used as appropriate. Lastly, univariate logistic regression was undertaken to examine variables that might be predictive of worsening cardiovascular imaging studies. The variables included were age, diabetes status, total and daily dose of calcium carbonate, total and daily dose of calcitriol, total dose of vitamin D, time on dialysis, and serum calcium, phosphate, and parathyroid hormone levels.

\section{Results}

Descriptive statistics are summarized in Tables 1-3. Approximately $68 \%$ of the patients were treated with hemodialysis and $32 \%$ with peritoneal dialysis. Of the hemodialysis patients, $70 \%$ had either an arteriovenous fistula or graft. The average access flow was $337 \mathrm{~mL} / \mathrm{min}$. Patients were placed on hold for a variety of reasons, including cardiovascular disease $(n=7)$, peripheral vascular disease $(n=4)$, infection $(n=3)$, other $(n=17)$, and unknown $(n=1)$. Active and on-hold patients did not differ significantly in terms of basic demographic data (Table 1). There was a trend towards a longer dialysis duration for those on hold compared with active wait-listed patients but this did not reach statistical significance $(1547 \pm 837.9$ versus $1234 \pm 867.5$ days; $P=0.09)$. A greater proportion of active wait-listed patients were taking vitamin D and calcitriol when compared with on-hold patients, but this was not statistically significant (Table 2).

The total dose of elemental calcium received for a waitlisted transplant candidate on dialysis was $1.75 \pm 1.7$ (range 0.033-9.56) kg (Table 3). This value was significantly higher in the on-hold population compared with the active wait-listed population $(2.35 \pm 1.94 \mathrm{~kg}$ versus $1.49 \pm 1.52 \mathrm{~kg}$; $P=0.02)$.

Of the 49 patients with two cardiac perfusion imaging studies, four (8\%) improved, 28 (57\%) remained unchanged, and $17(35 \%)$ worsened. Nineteen percent of active patients $(5 / 26)$ and $52 \%$ (12/23) of on-hold patients developed worsening cardiac perfusion imaging since being listed for a renal transplant $(P=0.02)$. In univariate analysis, total doses of calcium and calcitriol were associated with worsened cardiovascular imaging (Table 4). Although the ejection fraction did not change between the first and second studies for patients with improved/stable imaging $(62 \%, 64 \%)$ and the patients with worsened imaging $(57 \%, 58 \%)$, the improved/stable patients had a higher ejection fraction overall $(P=0.04)$.

\section{Discussion}

In this single-center retrospective analysis, patients with ESRD on dialysis received large amounts of calcium-based phosphate binders while waiting for a renal transplant. Specifically, an average ESRD patient on the transplant waiting list received $1.75 \pm 1.70 \mathrm{~kg}$ of elemental calcium. The amount of calcium carbonate prescribed was greater for patients who were on hold compared with those who were active on the transplant waiting list. Similarly, in univariate analysis, an increased total dose of calcium carbonate was associated with worsening of cardiovascular perfusion imaging studies. This same association was seen for increasing total calcitriol dose.

Time on dialysis before transplantation is associated with decreased patient and graft survival post-transplant. ${ }^{12}$ It remains unclear what specific factors contribute to the poor post-transplant outcomes for patients with prolonged pretransplant dialysis. Disorders of calcium and phosphate homeostasis or the medications that are used to treat them may be contributory. Aortic calcification in incident renal transplant patients is associated with cardiovascular events and mortality. ${ }^{12}$ In our study, increased total doses of elemental calcium and calcitriol were associated with worsening of cardiovascular perfusion imaging studies. In the National

Table I Population characteristics

\begin{tabular}{|c|c|c|c|c|}
\hline & Overall $(n=105)$ & Active $(n=73)$ & On-hold $(n=32)$ & $P$ value \\
\hline \multicolumn{5}{|l|}{ Gender } \\
\hline Male, n (\%) & $64(61.0)$ & $43(58.9)$ & $21(65.6)$ & 0.52 \\
\hline Female, n (\%) & $4 \mid(39.0)$ & $30(4 I . I)$ & II (34.4) & \\
\hline Mean age, years $( \pm S D)$ & $55.6 \pm 13.4$ & $54.9 \pm 14.5$ & $57.2 \pm 14.5$ & 0.43 \\
\hline Diabetes mellitus n (\%) & $34(32.4)$ & $22(30.1)$ & $12(37.5)$ & 0.46 \\
\hline Mean days on dialysis $( \pm S D)$ & $1329.4 \pm 866.7$ & $1234 \pm 867.5$ & $1547 \pm 837.9$ & 0.09 \\
\hline Dialysis modality (n) HD/PD/unknown & $72 / 30 / 3$ & $48 / 23 / 2$ & $24 / 7 / 1$ & 0.32 \\
\hline Mean serum calcium, mmol/L $( \pm S D)$ & $2.37 \pm 1.93$ & $2.47 \pm 2.31$ & $2.13 \pm 0.22$ & 0.21 \\
\hline Mean serum $\mathrm{PO}_{4}, \mathrm{mmol} / \mathrm{L}( \pm \mathrm{SD})$ & $1.74 \pm 0.49$ & $1.70 \pm 0.50$ & $\mathrm{I} .83 \pm 0.47$ & 0.2 \\
\hline Median serum PTH, pmol/L (IQR) & $26.7(14.9-45.7)$ & $24.5(14.8-46.3)$ & $30.0(20.2-44.2)$ & 0.8 \\
\hline
\end{tabular}

Abbreviations: HD, hemodialysis; IQR, interquartile range; PD, peritoneal dialysis; PTH, parathyroid hormone; SD, standard deviation. 
Table 2 Medications

\begin{tabular}{|c|c|c|c|c|}
\hline & Overall $(n=105)$ & Active $(n=73)$ & On-hold $(n=32)$ & $P$ value \\
\hline Calcium carbonate, n (\%) & $105(100)$ & $73(100)$ & $32(100)$ & 1 \\
\hline Calcitriol, n (\%) & $84(80.0)$ & $62(84.9)$ & $22(68.8)$ & 0.06 \\
\hline Vitamin D, n (\%) & $33(31.4)$ & $27(37.0)$ & $6(18.8)$ & 0.06 \\
\hline Cincalcet, $\mathrm{n}(\%)$ & $17(16.2)$ & II (I5.I) & $6(18.8)$ & 0.64 \\
\hline Lanthanum, n (\%) & $5(4.8)$ & $3(4.1)$ & $2(6.3)$ & 0.64 \\
\hline Niacin, n (\%) & $3(2.9)$ & $3(4.1)$ & 0 & 0.55 \\
\hline Sevelamer hydrochloride, $\mathrm{n}(\%)$ & I $(0.97)$ & $\mathrm{I}(\mathrm{I} .4)$ & 0 & I \\
\hline
\end{tabular}

Kidney Foundation Disease Outcomes Quality Initiative guidelines, the maximum suggested elemental calcium intake from medication is $1500 \mathrm{mg}$ per day, based on imprecise estimates of utilization and loss. ${ }^{13}$ Although our overall average daily intake was below this limit, patients on hold on the renal transplant waiting list were above this recommended value. Importantly, a recommended daily intake does not address the potential for long-term mineral accumulation, that is likely to be magnified as renal transplant waiting times increase. In the general population, a recent meta-analysis of calcium or calcium and vitamin D supplementation in post-menopausal women demonstrated an increased risk of myocardial infarction and the composite of myocardial infarction and stroke in women treated with supplements. ${ }^{14}$ The authors calculated that, for every 1000 patients treated for 5 years, there would be six additional myocardial infarctions and strokes to prevent three fractures. Furthermore, there did not appear to be a dose-response curve, such that doses $<500 \mathrm{mg}$ /day might be as harmful as doses $>1000 \mathrm{mg} /$ day.

For patients with ESRD, sevelamer hydrochloride and lanthanum are alternatives to calcium-based phosphate binders, but are more expensive. In our study, there was limited use of either of these medications, despite recent Kidney Disease: Improving Global Outcomes guidelines which recommend considering use of non-calcium-based phosphate binders for patients with ESRD and evidence of vascular calcification. ${ }^{15}$ This is consistent with a previous study showing that use of $>1500 \mathrm{mg}$ of elemental calcium per day was observed in regions with restricted access to sevelamer hydrochloride. ${ }^{16}$

Although higher serum vitamin D and vitamin D analogs have been associated with improved outcomes for patients on dialysis in some studies, the type of vitamin D may be important. ${ }^{17,18}$ In a study of rats treated with either calcitriol or oxacalcitriol, rats given calcitriol had evidence of vascular calcification which was not seen in rats treated with the vitamin D analog. ${ }^{19}$ Similarly, in a study examining over 60,000 patients on hemodialysis in the US, the risk of death was greater for patients treated with calcitriol than in patients treated with paricalcitol. ${ }^{20}$ The authors hypothesized that the benefit of paricalcitol was due to blunted gut absorption and bone resorption of calcium and phosphate, leading to lower mineral loads with a reduction in vascular calcification and cardiovascular death.

Our study has a number of limitations, including its observational retrospective design that only allows us to describe associations. The small sample size prevented us from adjusting for other cardiovascular risk factors in our analysis. Just under half of the patients had undergone two cardiac perfusion imaging studies, limiting assessment of progressive vascular disease to that subgroup. Our singlecenter experience is not likely to be representative of worldwide practice. We also assumed that the dose prescribed was the dose ingested, which may be an overestimate of true intake. Additionally, the total doses of calcium carbonate and calcitriol reported are only after development of ESRD, and do not include the management of mineral metabolism prior to that time.

Although our results are not new, we believe that the message is important. The data are suggestive of a potentially increased risk of morbidity in wait-listed patients with respect to transplant candidacy. As the waiting times for renal transplant continue to increase, the potential for "harm" on

Table 3 Medication doses

\begin{tabular}{|c|c|c|c|c|}
\hline & Overall $(n=105)$ & Active $(n=73)$ & On-hold $(n=32)$ & $P$ value \\
\hline Calcium carbonate, $\mathrm{mg} /$ day $($ mean $\pm \mathrm{SD}$ ) & $1416 \pm 766.2$ & $1349 \pm 717.0$ & $|568 \pm 86| .0$ & 0.18 \\
\hline Total dose of calcium carbonate, $\mathrm{kg}($ mean $\pm \mathrm{SD})$ & $1.75 \pm 1.70$ & $1.49 \pm 1.52$ & $2.35 \pm 1.94$ & 0.02 \\
\hline Daily dose of $1,25(\mathrm{OH})_{2} \mathrm{D}_{3}, \mu \mathrm{g}($ mean $\pm \mathrm{SD})$ & $0.25 \pm 0.25$ & $0.25 \pm 0.28$ & $0.27 \pm 0.15$ & 0.75 \\
\hline Total dose of $\mathrm{I}, 25(\mathrm{OH})_{2} \mathrm{D}_{3}, \mu \mathrm{g}($ mean $\pm \mathrm{SD})$ & $315.5 \pm 678.4$ & $288.5 \pm 750.7$ & $387.1 \pm 438.3$ & 0.46 \\
\hline
\end{tabular}

Abbreviation: SD, standard deviation. 
Table 4 Risk factors for worsening cardiovascular imaging

\begin{tabular}{|c|c|c|c|}
\hline & \multirow[t]{2}{*}{ Unit increase } & \multicolumn{2}{|c|}{ CV imaging outcome } \\
\hline & & OR (95\% Cl) & $P$ value \\
\hline Age & I year & $0.95(0.88-1.01)$ & 0.14 \\
\hline Diabetic status & & $1.96(0.58-6.56)$ & 0.28 \\
\hline Time on dialysis & I month & $1.04(0.996-1.08)$ & 0.08 \\
\hline Dialysis modality (HD/PD) & & $0.4(0.08-2.1)$ & 0.26 \\
\hline Calcium & 0.1 & $\mathrm{I} .05(0.79-\mathrm{I} .4)$ & 0.73 \\
\hline $\mathrm{PO}_{4}$ & 0.1 & $1.13(0.98-1.3)$ & 0.1 \\
\hline PTH & I & I.0I $(0.98-1.04)$ & 0.57 \\
\hline Daily dose of elemental calcium (mg) & $100 \mathrm{mg}$ & I.04 (0.97-I.I2) & 0.28 \\
\hline Total dose of elemental calcium (kg) & $\mathrm{l} \mathrm{kg}$ & $1.47(1.00-2.16)$ & 0.05 \\
\hline Daily dose of calcitriol $(\mu \mathrm{g})$ & $0.01 \mu \mathrm{g}$ & $1.06(I-1.14)$ & 0.07 \\
\hline Total dose of calcitriol $(\mu \mathrm{g})$ & $100 \mu g$ & $1.22(1.00-1.50)$ & 0.05 \\
\hline Total dose of vitamin $\mathrm{D}$ & $\mathrm{I} I \mathrm{IU}$ & $0.77(0.20-2.89)$ & 0.69 \\
\hline
\end{tabular}

Abbreviations: $\mathrm{Cl}$, confidence interval; CV, cardiovascular; HD, hemodialysis; OR, odds ratio; PD, peritoneal dialysis; PTH, parathyroid hormone; SD, standard deviation.

dialysis also increases. Even if the average daily dose of elemental calcium is within the recommended guidelines, dialysis patients will be in a positive calcium balance that will accumulate with prolonged renal transplant waiting times. In the general population, use of calcium or calcium and vitamin $D$ has been shown to increase the risk of myocardial infarction and stroke over 5 years regardless of dose. Further research is required to clarify the amount of elemental calcium required to maintain a neutral balance in patients with ESRD, especially with loss of residual renal function over time. Similarly, the most appropriate type of vitamin D remains to be clarified in randomized controlled trials. Lastly, no randomized controlled trial has demonstrated the benefits of lower serum phosphate, but high doses of calcium carbonate continue to be prescribed in Canada, with significant potential morbidity.

\section{Acknowledgments}

GAK and DLZ both receive salary support from the Department of Medicine, Ottawa Hospital.

\section{Disclosure}

DLZ has received honoraria and unrestricted educational grants from Genzyme, Canada. The other authors have no conflicts of interest to declare for this work.

\section{References}

1. Foley RN, Parfrey PS, Sarnak MJ. Clinical epidemiology of cardiac disease in chronic renal disease. Am J Kidney Dis. 1998;32:S112-S119.

2. London GM, Guerin AP, Marchais SJ, Metivier F, Pannier B, Adda H. Arterial media calcification in end-stage renal disease: impact on all cause and cardiovascular mortality. Nephrol Dial Transplant. 2003;18:1731-1740.

3. Block GA, Klassen PS, Lazarus JM, Ofsthun N, Lowrie EG, Chertow GM. Mineral metabolism, mortality and morbidity in maintenance hemodialysis. J Am Soc Nephrol. 2004;15:2208-2018.
4. Ribeiro S, Ramos A, Brandão A, et al. Cardiac valve calcification in haemodialysis patients: role of calcium-phosphate metabolism. Nephrol Dial Transplant. 1998;13:2037-2040.

5. Noordzij M, Cranenburg EM, Engelsman LF, et al; for the NECOSAD Study Group. Progression of aortic calcification is associated with disorders of mineral metabolism and mortality in chronic dialysis patients. Nephrol Dial Transplant. 2011;26:1662-1669.

6. Chertow GM, Burke SK, Paolo R; for the Treat To Goal Working Group. Sevelamer attenuates the progression of coronary and aortic calcification in hemodialysis patients. Kidney Int. 2002;62:245-252.

7. Suki WN, Zabaneh R, Cangiano JL, et al. Effects of sevelamer and calcium-based phosphate binders on mortality in hemodialysis patients. Kidney Int. 2007;72:1130-1137.

8. Block GA, Raggi P, Bellasi A, Kooienga L, Speigel DM. Mortality effect of coronary calcification and phosphate binder choice in incident hemodialysis patients. Kidney Int. 2007;71:438-441.

9. Canadian Institute for Health Information. Canadian Organ Replacement Register Annual Report: Treatment of End-Stage Organ Failure in Canada, 2000 to 2009. Ottawa, Ontario: Canadian Institute for Health Information; 2011.

10. Leichtman AB, Cohen D, Keith D, et al. Kidney and pancreas transplantation in the United States, 1997-2006: the HRSA breakthrough collaborative and the 58 DSA challenge. Am J Transplant. 2008;8: 946-957.

11. http://www.organdonation.nhs.uk/ukt/about_transplants/waiting_time_ to_transplant/waiting time_to_transplant.asp.

12. DeLaoch SS, Joffe MM, Mai X, Goral S, Rosas SE. Aortic calcification predicts cardiovascular events and all-cause mortality in renal transplantation. Nephrol Dial Transplant. 2009;24:1314-1319.

13. National Kidney Foundation. K/DOQI clinical practice guidelines for bone metabolism and disease in chronic kidney disease. Am J Kidney Dis. 2003;42(4 Suppl 3):S1-S201.

14. Bolland MJ, Grey A, Avnell Allison, Gamble GD, Reid IR. Calcium supplements with or without vitamin D and risk of cardiovascular events: reanalysis of the women's health initiative limited access data set and meta-analysis. BMJ. 2011;342:d2040.

15. Kidney Disease: Improving Global Outcomes (KDIGO) CKD-MBD Work Group. KDIGO clinical practice guideline for the diagnosis, evaluation, prevention, and treatment of chronic kidney disease-mineral and bone disorder (CKD-MBD). Kidney Int Suppl. 2009;113:S1-S130.

16. Lebner, AC, Beard KM, Soroka SD, et al. Interprovincial differences in the achievement of K/DOQI targets of mineral metabolism in Canada. Nephrol Dial Transplant. 2011;26:156-163.

17. Wolf M, Shah A, Gutierrez O, et al. Vitamin D levels and early mortality among incident hemodialysis patients. Kidney Int. 2007; 72:1004-1013. 
18. Shoji T, Shinohara K, Kimoto E, et al. Lower risk for cardiovascular mortality in oral 1alpha-hydroxy vitamin D3 users in a haemodialysis population. Nephrol Dial Transplant. 2004;19:179-184.

19. Hirata M, Katsumata K, Endo K, Fukushima N, Ohkawa H, Fukagawa M. In subtotally nephrectomised rats 22-oxacalcitriol suppress parathyroid hormone with less risk of cardiovascular calcification or deterioration of residual renal function than $1,25(\mathrm{OH})_{2}$ vitamin D3. Nephrol Dial Transplant. 2003;18:1770-1776.
20. Teng M, Wolf M, Lowrie E, Ofsthun N, Lazarus JM, Thadhani R. Survival of patients undergoing hemodialysis with paricalcitol or calcitriol therapy. N Engl J Med. 2003;349:446-456.

\section{Publish your work in this journal}

Transplant Research and Risk Management is an international, peerreviewed open access journal focusing on all aspects of transplantation and risk management to achieve optimal outcomes in the recipient improving survival and quality of life. The journal welcomes submitted papers covering original research, basic science, clinical studies, reviews \& evaluations, guidelines, expert opinion and commentary, case reports and extended reports. The manuscript management system is completely online and includes a very quick and fair peer-review system, which is all easy to use. Visit http://www.dovepress.com/ testimonials.php to read real quotes from published authors. 